\title{
PRÁTICAS PEDAGÓGICAS DE EDUCAÇÃO AMBIENTAL NA ESCOLA ESTADUAL INDÍGENA TUPINAMBÁ DO ACUÍPE DE BAIXO EM ILHÉUS (BA)
}

\author{
Matheus Bezerra de Oliveira1 \\ Alessandra Buonavoglia Costa-Pinto² \\ Angela Maria Garcia ${ }^{3}$
}

\begin{abstract}
Resumo: O objetivo maior da Educação Ambiental (EA) é fomentar a conservação da biodiversidade, considerando também a autorrealização individual, social e comunitária. Com a pesquisa que resultou nesse trabalho, objetivou-se identificar como se dão as práticas pedagógicas de Educação Ambiental no Colégio Estadual Indígena Tupinambá de Acuípe de Baixo em Ilhéus (BA). Aplicou-se uma metodologia qualitativa, através de pesquisa bibliográfica e coleta de dados, por meio da Matriz de Indicadores de Educação Ambiental para Avaliação da Sustentabilidade Socioambiental na Escola, no intento de produzir um estudo de caso da Educação Ambiental Indígena na escola Destaque-se que no decorrer da pesquisa percebeu-se que a EA existente na escola possui importantes saberes e práticas que precisam ser valorizadas e que podem inclusive serem replicadas em outras escolas e assim contribuir para implementação de uma EA crítica, transversal e continuada.
\end{abstract}

Palavras-chave: Educação Indígena; Legislação Educacional; Meio Ambiente; Políticas Públicas.

Abstract: The main objective of Environmental Education (EE) is to promote the conservation of biodiversity, also considering individual, social and community selfrealization. With the research that resulted in this work, the objective was to identify how to take place as pedagogical practices of environmental education at the Tupinambá Indigenous State College of Acuípe de Baixo in Ilhéus (BA, Brazil). A qualitative methodology was applied, through bibliographical research and data collection, through the Matrix of Environmental Education Indicators for the Assessment of Socioenvironmental Sustainability at School. In addition, questionnaires and attributes with teachers, managers and school leaders were included, to produce a case study of Indigenous Environmental Education at school. important knowledge and practices that need to be valued and that can include being replicated in other schools and thus contributing to the implementation of a critical, transversal and continuous EE.

Keywords: Indigenous Education; Educational Legislation; Environment; Public Policy.

\footnotetext{
1 Universidade Federal do Sul da Bahia. E-mail: bezerraadvocaciaios@gmail.com

2 Universidade Federal do Sul da Bahia. E-mail: alegubcp@gmail.com

3 Universidade Federal do Sul da Bahia. E-mail: angelagarciaufsb@gmail.com
} 


\section{Introdução}

Os Parâmetros Curriculares Nacionais para a educação escolar brasileira não são tradicionalmente sustentáveis, ou seja, não estão voltados à construção do sujeito ecológico, conforme nos indica Isabel Carvalho (2004). Os fazeres pedagógicos que promovem a questão ambiental podem ser considerados uma novidade, visto que a Lei no 9.795 que institui a Política Nacional de Educação Ambiental (PNEA) só foi promulgada em 27 de abril de 1999, a Política Estadual de Educação Ambiental da Bahia só no ano de 2011 e as Diretrizes Curriculares Nacionais para a Educação Ambiental do MEC apenas em 2012.

Entretanto, vale salientar que a Educação Ambiental deve ser um processo permanente inserido no âmbito da educação, em virtude da sua capacidade de contribuir com fomento de reflexões e da compreensão das relações sócio-históricas entre sociedade-natureza. De forma que os indivíduos e coletividades possam despertar para a necessidade de uma atuação intervencionista e mediadora nos conflitos e problemas ambientais, assumindo uma postura ativa de mudança de realidade social.

Foi exatamente em reconhecimento à importância da Educação Ambiental que a nossa Carta Magna (CF/88) trouxe em seu artigo 225, inciso VI a garantia constitucional que determina ao poder público a incumbência de "promover a Educação Ambiental em todos os níveis de ensino e a conscientização pública para a preservação do meio ambiente".

No âmbito estadual, o Poder Público da Bahia, por meio da Lei 12.056/11, instituiu a Política Estadual de Educação Ambiental que visa articular a Educação Ambiental, além de fortalecer o seu papel junto à gestão ambiental como um todo, o que figura como um importante avanço legislativo dentro do Estado, sobretudo por seu caráter inovador. Imperioso destacar ainda que, no âmbito municipal, também podem existir leis que a assegurem, no caso as Políticas Municipais de Educação Ambiental,

Assim, podemos inferir que legislativamente em nosso país a Educação Ambiental encontra-se amparada por diversos entes da Administração Pública. Contudo, são inúmeros os exemplos de que a sociedade brasileira ainda não possui uma Educação Ambiental de qualidade, crítica e transformadora que proporcione a construção de sociedades sustentáveis, no mais amplo sentido dos termos, além de uma patente necessidade de conscientização lastreada em valores éticos e sociais.

Inclusive, o documento produzido pelo Ministério da Educação brasileiro intitulado "O que fazem as Escolas que dizem que fazem Educação Ambiental?" (MEC, 2007), nos mostra que a universalização do acesso à Educação Ambiental no Brasil atual encapsula um número significativo de desafios que podem e devem ser identificados, a partir da realização de uma pesquisa em profundidade no próprio loco do processo pedagógico: a escola. Ressalte-se que foi exatamente neste sentido que se propôs esta pesquisa, 
buscando identificar os desafios para uma conscientização sobre a necessidade da preservação ambiental e cultural.

Ademais, a situação fica ainda mais periclitante quando observamos a realidade dos povos tradicionais, que após serem submetidos a uma educação afastada dos seus valores habituais, encontram-se vulneráveis e sem políticas públicas que atuem na proteção do meio ambiente e na construção de sociedades locais sustentáveis, levando em consideração a conservação da natureza, a sustentabilidade da sociedade e a sustentabilidade da economia. É o que se observa nos povos indígenas tradicionais do Sul da Bahia, onde comunidades resistem culturalmente há mais de 500 anos, apesar da imposição violenta de outras culturas, onde permanecem lutando para manter suas tradições.

Importante destacar que a educação não formal indígena sempre foi sustentável, por que o que chamamos hoje de sustentabilidade são procedimentos, ações humanas ou modos de vida que foram sistematizados e institucionalizados sob a forma de lei, diretrizes etc., em que os seres humanos com a mentalidade de domínio e uso da natureza em benefício próprio e para acumular riqueza e poder viram a necessidade de se educar para a sustentabilidade e a sistematizaram.

Porém, o fato é que em função da nova realidade que os povos indígenas estão inseridos e até mesmo em função da relação intrínseca com o meio ambiente, inclusive por conta da sua localização em contato direto com o meio ambiente e com a comunidade, vislumbra-se que as comunidades indígenas também necessitem de uma Educação Ambiental alinhada com as políticas públicas da área que propõem justamente essa relação de amizade e respeito entre a sociedade humana e a natureza, criando entre eles relações de afeto, seguindo o raciocínio de Espinosa, conforme nos mostra a estudiosa CostaPinto (2002, p.25):

Assim, a EA deve, seguindo o raciocínio de Espinosa, promover o desvelar da cadeia dos afetos sociais que deram origem à situação atual, estimulando a libertação do sujeito do medo e da servidão, mobilizando-o para ação transformadora (alegria), fortalecendo-o para participar das tomadas de decisão e do delineamento de alternativas, socialmente justas e ecologicamente mais equilibradas, na busca por solucionar os problemas que afetam sua vida individual e social.

Ressalte-se que a Lei de Diretrizes e Bases da Educação Nacional - LDB de 1996 e legislações subsequentes determinam que a educação indígena tenha um tratamento diferenciado em relação às demais escolas. Contudo, na prática é perceptível que não há um pleno cumprimento da legislação, observase que os Poderes Executivos não ofereceram condições para isso. 
Nesta linha de conexão, a mola propulsora do presente trabalho reside na análise de um estudo de caso no intento de identificar o que vem sendo feito na escola pesquisada no que se refere às práticas de Educação Ambiental. E a partir disso começarmos a buscar e pensar novas estratégias que façam valer a legislação aplicável, contribuindo como instrumento de retomada da identidade cultural indígena, o que inclui a retomada de atitudes e comportamentos consoantes com a conservação da natureza.

Para este exercício de reflexão, como recorte metodológico, analisou-se como essa perspectiva legal da Educação Ambiental é posta em prática na Escola Estadual Indígena Tupinambá de Acuípe de Baixo, situada no município de llhéus-BA. Em assim sendo, a problemática envolve o seguinte questionamento: como acontecem as práticas pedagógicas de Educação Ambiental ocorridas em sede do Colégio Estadual Indígena Tupinambá de Acuípe de Baixo em llhéus - BA?

O problema supracitado torna-se relevante na medida em que, observando-se as legislações em vigência, percebe-se que todas caminham num mesmo sentido e corroboram na ideia de que o Poder Público deve garantir uma Educação Ambiental de qualidade. Porém, é nesse contexto que a presente pesquisa visa demonstrar que na atuação prática o Poder Público é insuficiente, negligenciando na promoção de políticas públicas que atinjam os fins postos nas leis, como se verá mais adiante.

A inquietação aqui aventada com relação à problemática da Educação Ambiental busca como resultado identificar os efeitos reais produzidos por essas leis e as dificuldades que a escola enfrenta para colocar isso em prática dentro do sistema escolar, para assim dar um retorno ao Poder Público e às instituições de ensino, bem como à sociedade em geral, sobretudo à população local, para que possam refletir, questionar e buscar a efetivação seus direitos através de políticas públicas, despertando uma consciência social e ambiental como forma de melhoria da qualidade de vida, contribuindo assim para o desenvolvimento de toda a sociedade e para a conservação da natureza a um só tempo.

Ao se identificar o retrato da realidade da Educação Ambiental indígena na escola pesquisada espero estar contribuindo para com todos os profissionais envolvidos com a educação e promoção de políticas públicas, ao poder judiciário e à sociedade em geral. Desta forma, o objetivo maior desta pesquisa foi conhecer e analisar o processo educacional ambientalista da Escola pesquisada e identificar como está o seu desenvolvimento, observando ainda se está de acordo com previsto na legislação nacional. 


\section{Material e Métodos}

O satisfatório desenvolvimento da pesquisa requereu a utilização de uma metodologia qualitativa por meio de um Estudo de Caso da escola indígena Tupinambá do Acuípe de Baixo, metodologia que permitiu a análise das práticas de EA já desenvolvidas pela instituição escolar. Assim, a presente investigação científica realizou-se por meio de uma abordagem qualitativa caracterizada pelo trabalho que parte da realidade social e que busca a compreensão dos fenômenos humanos, dos significados, dos motivos, das aspirações, das crenças dos valores, das atitudes e das representações (MINAYO, 2015).

Para tanto, utilizando-se das lições de Goode e Hatt (1968, apud PEDRINI 2007 , p. 76), percebeu-se que para atingir os objetivos da pesquisa era viável a realização de um estudo de caso, tendo em vista que:

[...] quando se deseja estudar algo singular, que valha por si mesmo. Pode ser similar a outros, mas também distinto, por ser singular. Isto é parecer inicialmente único, mesmo que posteriormente evidencie similaridades com outros casos e, assim, aumentar sua capacidade generalizadora.

Imperioso trazer ainda as lições de Ludke e André (1996), quando demonstram que o estudo de caso tem como interesse a investigação sistemática de uma instância específica. Destacando ainda que é possível que o leitor perceba que o caso estudado se assemelhe em alguns aspectos a outros casos particulares, pelo que pode ocorrer a "generalização naturalística" proposta por Stake.

Ludke e André (1996), ainda concluem que ao retratar o cotidiano escolar em toda a sua riqueza, esse tipo de pesquisa oferece elementos preciosos que permitem melhor compreensão da escola e das suas relações com a sociedade. Em razão do acima exposto é que se vislumbra que a realização de um estudo de caso, é um método adequado aos objetivos da pesquisa e poderá contribuir inclusive com demais pesquisas que buscam mapear a EA no Brasil.

O percurso metodológico da presente pesquisa iniciou-se pela análise de títulos, resumos e artigos completos que abordaram a temática Educação Ambiental, seus conceitos, histórico, amparo legal, além dos tipos de EA e suas características.

Vale destacar que o estudo abarcou uma longa pesquisa bibliográfica sobre os temas acima, destacando ainda a realização de uma ampla análise da legislação referente ao tema nos mais diferentes entes da Federação brasileira e até mesmo por meio dos Acordos Internacionais, que através de sua importância indiscutível trouxeram grandes avanços ao Direito e à Educação Ambiental. Nesse sentido, esclarece Boccato (2006, p. 266), 
A pesquisa bibliográfica busca a resolução de um problema (hipótese) por meio de referenciais teóricos publicados, analisando e discutindo as várias contribuições científicas. Esse tipo de pesquisa trará subsídios para 0 conhecimento sobre o que foi pesquisado, como e sob que enfoque e/ou perspectivas foi tratado o assunto apresentado na literatura científica. Para tanto, é de suma importância que o pesquisador realize um planejamento sistemático do processo de pesquisa, compreendendo desde a definição temática, passando pela construção lógica do trabalho até a decisão da sua forma de comunicação e divulgação.

Já no que se refere à temática indígena, sobretudo ao conteúdo específico do Povo Indígena Tupinambá, a maior parte da bibliografia foi indicada por lideranças e pesquisadores indígenas, vez que se trata de um processo histórico e cultural específico. Inclusive, dados obtidos nas pesquisas revelam que os trabalhos que trazem essa temática são investigados em sua maioria por estudantes indígenas, que ao adentrarem a Academia retornam os seus estudos para a Aldeia de onde vieram, se atendo assim a estudar sobre 0 seu próprio povo, sua história e cultura.

A pesquisa bibliográfica incluiu ainda o estudo antropológico e cosmológico sobre o povo indígena pesquisado, abarcando o seu histórico, seus modos de vida ("modo de ser e viver"), de produção e a relação com o território, bem como com o estudo das Diretrizes da Educação Indígena e sua diferenciação e especificidades. Neste momento, mostra-se valioso trazer as palavras de Tassinari e Cohn (2012), quando afirmam que

Quando pensamos nos impasses da educação escolar indígena, os maiores riscos parecem estar exatamente em imaginar ou esperar que a escola possa se tornar uma -instituição nativall, se diluir no cotidiano indígena, ou em desconhecer a efetiva diferença que está não só nos conhecimentos escolares, como nos modos de conceber o conhecimento, sua produção, aquisição e expressão. A noção de fronteira nos auxilia exatamente a manter a diferença que deve conviver nas práticas escolares. É disso, afinal, que se trata a interculturalidade, e é só assim que os conhecimentos indígenas e não indígenas poderão, eventualmente, se comunicar, em vez de caminhar em paralelo (TASSINARI; COHN, 2012, p. 268).

Por isto, torna-se necessário nos aliarmos com a pesquisa etnográfica, no sentido de tentar compreender os modos de viver de cada povo e como isso tem se refletido na escola. Segundo André (1995), etimologicamente, etnografia significa descrição cultural, e, para os antropólogos, o termo possui dois sentidos: (i) conjunto de técnicas para coletar dados sobre os valores, hábitos, crenças, práticas e comportamentos de um grupo social; (ii) relato escrito que resulta do emprego dessas técnicas.

Vale destacar que o uso da etnografia nas pesquisas em Educação vem crescendo durante as últimas décadas e, por meio dela, é possível que se compreenda "de dentro" os fenômenos educacionais (ESTEBAN, 2010). Por isso foi importante durante a pesquisa utilizarmos dos relatos orais e das 
memórias descritas pelas lideranças e integrantes do movimento indígena. Vale aqui colacionar as palavras de Magalhães que nos afirma

As memórias orais e escritas, provenientes de documentos e das memórias dos moradores mais velhos, respectivamente, foram agregadas pelas lideranças Tupinambá para construir um conjunto de testemunhos sobre as ações por parte de grupos sociais que atingiram diretamente os caboclos de Olivença. Não se trata, absolutamente, de conferir às histórias - estatuto do fabricado artificialmente para garantir bens materiais, a posse da terra e serviços públicos como saúde e educação. Compreender a utilização das narrativas sobre a própria história significa apreender uma das formas por meio das quais os atores sociais, os indígenas de Olivença, começaram a reconhecer a existência de um passado e presente comuns, a partir de um diálogo, propiciado pela mediação e divulgação das educadoras do CAPOREC, prenhe de experiências familiares. Este diálogo proporcionou uma nova articulação das vinte e três comunidades em torno de um objetivo: fazer com que o Estado os reconhecesse como indígenas (2010, p. 57-58).

Já de acordo com Minayo e Sanches (1993), o conhecimento científico sempre transcorre como a busca de articulações entre teoria e realidade, tendo como fio condutor o método, com a função fundamental de articular e fundamentar esses conhecimentos de maneira a proporcionar um caminho claro de investigação. Em razão disto, além do campo teórico, esta pesquisa utilizou na sua metodologia a pesquisa de campo, que se deu por etapas, dentre elas, a realização de entrevistas semiestruturada e aplicação da Matriz de Indicadores de Educação Ambiental proposta por Vieira, Campos e Morais (2016, p.114) e devidamente adaptada para a realidade local, o que possibilitou a interação com os indivíduos e as comunidades pesquisadas com captação das informações desejadas de forma mais pessoal e íntima, inclusive permitindo o aprofundamento de pontos percebidos por outras técnicas.

A matriz utilizada serviu como um roteiro para guiar as entrevistas, e segundo Ludke e André (1996), tal instrumento é aconselhável, pois permite que a entrevista siga naturalmente uma ordem lógica e psicológica, permitindo que haja uma sequência lógica entre os assuntos.

Vale destacar que os sujeitos da pesquisa foram os professores da Escola Indígena Tupinambá de Acuípe de Baixo em llhéus - BA. Frise-se que a escola conta hoje com um total de 19 professores e destes foi possível entrevistar 11, sendo que entre eles estavam líderes da comunidade que também atuam como professores, a exemplo do Cacique.

Os sujeitos da pesquisa totalizam 11 participantes, sendo nove professores da escola, além da sua gestora e do Coordenador da Educação 
Indígena do Estado da Bahia, que também é Tupinambá de Olivença e já atuou como professor da instituição pesquisada. As entrevistas foram realizadas por conveniência dos entrevistados, que participaram por adesões livres e voluntárias. Destaque-se que foram convidados todos os professores da escola e, por possibilidade e interesse, eles compareceram com o objetivo de colaborar com a pesquisa na temática ambiental, considerando o contexto de pandemia vivenciado no período da pesquisa.

A matriz de indicadores de Educação Ambiental utilizada foi proposta por Vieira, Campos e Morais (2016, p.114), apresenta 10 indicadores, organizados nas três dimensões da Educação Ambiental: gestão, currículo e espaço físico. Cada dimensão é constituída por um grupo de indicadores, que serão avaliados por cinco questões descritoras, com três opções de resposta: frequente $(\mathrm{F})$, eventual $(\mathrm{E})$ e nunca $(\mathrm{N})$, as quais contemplam a complexidade de uma educação integral e sustentável. Para aplicação na comunidade escolar pesquisada foram necessárias alterações e até mesmo supressão de algumas questões que não se adequavam à realidade da escola. Foram alteradas as questões $09,15,22,23,24,25,27,28,31,32$ e 39 . E retiradas as questões $03,07,08,28,32,33,34$, por não serem condizentes ou relevantes com os objetivos desta pesquisa.

Desta forma, a primeira dimensão, que trata sobre a gestão, foi dividida em 4 indicadores: gestão; gestão e comunicação; instâncias colegiadas; suficiência de recursos humanos e financeiros. O primeiro indicador busca entender se a gestão escolar é democrática, no sentido de observar se são construídos espaços participativos na escola, onde se valoriza a participação de alunos, professores, pais e gestores. Já o indicador de gestão e comunicação, trata da forma de planejamento e gestão democrática e comunitária na escola. Já o terceiro indicador, analisa a atuação das instâncias colegiadas como Conselho Escolar, lideranças comunitárias. Por fim, no último indicador desta dimensão, trabalhou-se a respeito da suficiência de recursos humanos e financeiros da escola e de sua manutenção, bem como no que se refere ao desenvolvimento de atividades de EA.

A segunda dimensão, por sua vez, trata sobre a dimensão de indicadores do currículo escolar. Esta dimensão foi dividida em três indicadores organização curricular; atividades e práticas pedagógicas; projetos e programas. O primeiro indicador que aborda a organização curricular, foram considerados a forma em que a escola trabalha a EA, na prática e em seus documentos oficiais, como o Projeto Político Pedagógico. Já o segundo indicador, que trata sobre atividades e práticas pedagógicas analisou as práticas pedagógicas desenvolvidas na escola para abordar a EA, inclusive levando em consideração aspectos culturais. E por fim, o indicador de projetos e programas que trata sobre os projetos e programas que trabalham a temática do meio ambiente e cultura, bem como sobre a participação da comunidade.

A terceira e última dimensão aborda o espaço físico da escola e do seu entorno, sendo dividida entre território da escola e entorno; infraestrutura e 
ambiente educativo; ecoeficiência. O indicador de território da escola e entorno evidencia o uso dos espaços da escola e do seu entorno nas práticas pedagógicas. Já no indicador seguinte é contemplado a infraestrutura da escola e equipamentos, bem como a acessibilidade e mobilidade. Por fim, o último indicador retrata o equilíbrio entre a eficiência e o impacto ambiental, abordando ações de coleta seletiva e consumo de água e energia e de segurança alimentar.

Os autores Vieira, Campos e Morais (2016, p.116), destacam que as respostas permitem avaliar a sustentabilidade socioambiental da escola quanto àquele indicador, quanto às dimensões da Educação Ambiental e quanto à escola (total) em relação a espaço educador sustentável. Bem como, identificam a possibilidade de quantificação destes indicadores e a atribuição de valores às respostas das questões descritoras. E com a avaliação realizada foi possível diagnosticar as potencialidades e os limites/fragilidades socioambientais do ambiente da escola, utilizando esses indicadores como instrumentos de avaliação, mensuração (medição) e de automonitoramento.

Adequando as alterações realizadas neste estudo, foram consideradas as seguintes pontuações: 2 pontos para as respostas frequentes $(F), 1$ ponto para as respostas eventuais (E) e valor zero $(0)$ ponto para as respostas nunca $(N)$. Como a matriz de indicadores possui 40 questões, será possível chegar ao total de 80 pontos. Quanto mais próximo a 80 pontos, supõe-se que a escola está no caminho da sustentabilidade socioambiental.

Usando essa tabulação inicialmente proposta pelos autores responsáveis pela matriz, mas com as devidas alterações, foi possível verificar a pontuação de cada indicador realizando a soma dos pontos das respostas das questões descritoras de cada uma das dimensões: gestão, currículo e espaço físico. Além dessa tabulação, é importante destacar que a Matriz foi utilizada para guiar o entrevistador. No entanto, entre as questões foram realizados outros questionamentos guiados por meio do díalogo e das informações trazidas pelos entrevistados relacionadas à história da escola, da comunidade e também das questões ambientais existentes. Assim, foram analisados também os discursos dos entrevistados no sentido de colaborar com os resultados obtidos.

\section{Resultados e Discussão}

Com o objetivo de tabular os dados obtidos por meio das entrevistas, foram dados valores numéricos às respostas, na dimensão de Gestão foram realizadas 16 perguntas, na dimensão Currículo, 11, e na Dimensão espaço, 13, tudo conforme a matriz em anexo. Como após as adaptações a matriz ficou com 40 questionamentos, seria possível chegar a 80 pontos por entrevistado, sendo que quanto mais próximo aos 80 pontos supõe-se que a escola está atendendo aos indicadores. No presente caso, por serem ouvidos 10 entrevistados, sendo 9 professores e a gestora escolar, o valor total máximo seriam 800 pontos, sendo 320, 220 e 260 os máximos por dimensão, respectivamente (Tabela 1$)$.

revista brasileira educação ambiental 
Tabela 1: Demonstração do total de pontos obtidos por dimensão de cada entrevistado.

\begin{tabular}{|c|c|c|c|c|}
\hline Entrevistado & Gestão & Currículo & Físico & Total \\
\hline$A$ & 22 & 20 & 22 & 64 \\
\hline$B$ & 23 & 18 & 14 & 55 \\
\hline C & 21 & 19 & 21 & 61 \\
\hline $\mathrm{D}$ & 22 & 20 & 16 & 58 \\
\hline$E$ & 26 & 21 & 12 & 59 \\
\hline $\mathrm{F}$ & 20 & 16 & 10 & 46 \\
\hline G & 20 & 18 & 14 & 52 \\
\hline $\mathrm{H}$ & 23 & 21 & 15 & 59 \\
\hline I & 18 & 15 & 14 & 47 \\
\hline$J$ & 25 & 19 & 18 & 61 \\
\hline 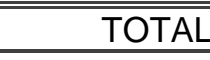 & 220 & 187 & 155 & 560 \\
\hline
\end{tabular}

Fonte: M. B. Oliveira.

Assim, por meio dessa avaliação é possível inferir que a escola atingiu os indicadores da matriz em $70 \%$ dos questionamentos realizados, um resultado bastante positivo diante da realidade das escolas públicas no Brasil. $\mathrm{Na}$ Dimensão da Gestão, o total atingido foi de 220 pontos, o que equivale a aproximadamente a $69 \%$ de cumprimento aos indicadores da dimensão.

Já no que se refere à dimensão do currículo, a quantidade de pontos obtidos foi de 187, de um total de 220 que poderiam ser obtidos, pelo que temos o percentual de $85 \%$ do total de satisfação dos indicadores. Por fim, na dimensão de espaço físico, o total de pontos obtidos foi de 155 , o que equivale a aproximadamente $60 \%$ do total de indicadores, perfazendo a média mais baixa entre as dimensões, conforme se pode visualizar na Figura 1:

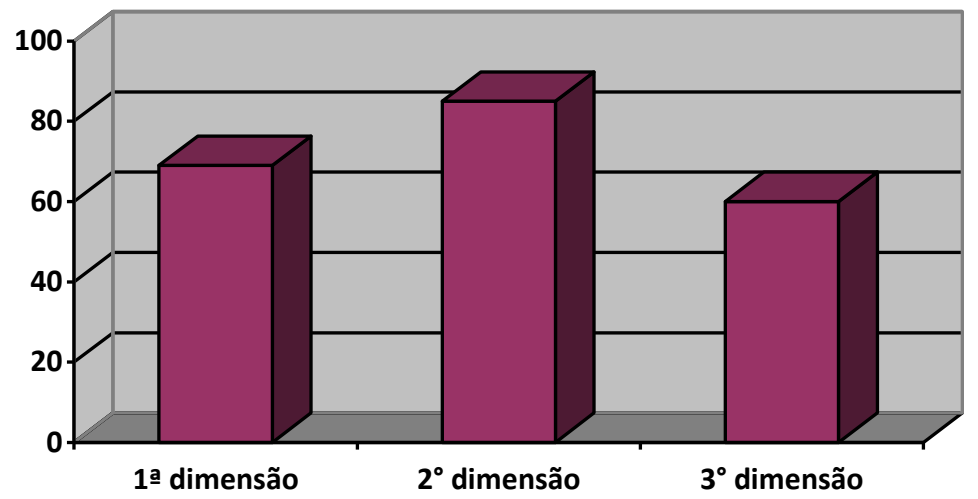


Neste momento, é imperioso destacarmos que o uso da matriz, compõe um grupo de métodos utilizados e que, apesar das informações dispostas acima já nos trazerem alguns dados importantes, iremos analisá-las na sua complexidade e buscar entender de forma mais minuciosa esses resultados, pelo que abordaremos abaixo cada dimensão, trazendo as visões dos entrevistados.

Na dimensão de Gestão, foram realizados questionamentos que incluem perguntas a respeito da gestão, pelo que se buscou saber sobre os espaços participativos e a inclusão de professores, funcionários, direção e alunos na tomada de decisões e na formação dos documentos da escola, a exemplo do Projeto Político Pedagógico. Buscou-se, ainda, saber sobre a presença de lideranças ativas na escola, bem assim do Conselho escolar, e por fim, a suficiência de recursos repassados à escola para a sua manutenção e formação do corpo docente, de funcionários e apoio pedagógico. Como visto no gráfico acima, nesta dimensão, a escola obteve a $69 \%$ (sessenta e nove por cento) de cumprimento aos indicadores. No entanto, neste momento colecionaremos alguns recortes das falas dos sujeitos da pesquisa sobre esses indicadores seguidas de alguns comentários.

Sobre a própria gestão da escola, de acordo com as entrevistas, podemos inferir que se trata de uma escola bastante democrática e participativa, onde todos têm lugar de fala na resolução de demandas e tomada de decisões. Assim, de acordo com a pontuação obtida e com os relatos dos entrevistados, podemos inferir que o conceito de escola democrática e comunitária é amplamente aplicável à escola estudada, de forma que todos têm lugar de falar e a direção e lideranças se preocupam em incluir a comunidade no contexto escolar e exploram e respeitam a opinião de todos, percebendo assim na prática a implementação de uma gestão participativa e democrática, considerada elemento fundamental para alcançar a qualidade da educação:

Tem-se como indicativo que para uma gestão democrática na escola é necessário um trabalho coletivo, o que não é meta fácil de atingir. A condução de processos que conduzam a um novo processo decisório responsável e comprometido neste trabalho coletivo, entendida como gestão democrática, poderá ser um dos caminhos para que a escola se insira num processo pedagógico eficiente orientado para a qualidade e eficácia da educação desejada para todos (ROSENAU, 2002, p. 7).

A necessidade de uma administração democrática está prevista na Constituição Federal de 1988 e na Lei de Diretrizes e Bases por meio do art. 14, que impõe que que todos os segmentos da comunidade escolar devem estar envolvidos nas decisões e nas atividades de gestão escolar.

Destaque-se que uma gestão participativa e democrática afasta essa dualidade entre os conhecimentos técnicos e populares e auxilia justamente na 
mudança desse paradigma, permitindo a construção de uma realidade que deixa o antagonismo de lado, promovendo espaços de discussão e aprendizagem, compreendendo que a comunidade detém seus próprios líderes, educadores, conhecimentos e modos de vida.

Percebe-se que as metodologias escolares não são únicas, mas que pode ser específica e baseada nos costumes e tradições daquela comunidade, bem assim podem ser construídas pela coletividade, incluindo os saberes e problemas locais no cotidiano pedagógico e possibilitando que as práticas sejam contextualizadas com as vivências.

Desta forma, a escola pesquisada por si só já demonstra uma tendência e organização própria com objetivo de incluir toda a comunidade na tomada de decisões e aliar as vivências e saberes populares ao conhecimento técnico de acordo com os seus interesses.

Destaque-se aqui o fato da escola não possuir muros, ser integrada ao meio ambiente e de toda a comunidade ter pleno acesso às suas dependências, pode fortalecer os laços e promover a conscientização sobre a responsabilidade de cuidar e preservar o espaço público que é a escola e de valorização do meio ambiente. Os alunos possuem bastante liberdade em todo espaço, podendo transitar livremente pelos espaços o que os coloca em contato direto com a natureza e com a comunidade, fugindo dos parâmetros tradicionais e engessados da maioria das escolas não indígenas, o que também a coloca em uma situação de vantagem quanto o desenvolvimento de atividades de EA.

Sobre a gestão e comunicação, as perguntas buscaram identificar a formação do Projeto Político Pedagógico, que conforme até já demonstrado acima, foi construído a várias mãos com a presença de todos os segmentos da escola. Segundo Moacir Gadotti (1994, p.34), a elaboração do projeto políticopedagógico permite uma mudança de concepção sobre a escola pública, em que passa de "aparelho burocrático do Estado" para uma escola que reflete as conquistas da comunidade.

Gadotti e Romão (1997) afirmam ainda que a participação comunitária influencia na melhoria da qualidade de ensino, pois, por meio dela, todos os segmentos da comunidade podem compreender melhor o funcionamento da escola e conhecer com mais profundidade os que nela estudam e trabalham, intensificar seu envolvimento com ela e, assim, acompanhar melhor a educação ali oferecida.

A construção coletiva do projeto político-pedagógico, assim como foi realizado na CEITAB é fundamental para a democratização e autonomia da escola. Para Veiga (2009, p. 14), a principal possibilidade de construção do projeto político-pedagógico passa pela relativa autonomia da escola, de sua capacidade de delinear sua própria identidade. Isto significa resgatar a escola como espaço público, lugar de debate, do diálogo, fundado na reflexão coletiva.

Portanto, é preciso entender que o projeto político- pedagógico da escola dará 
indicações necessárias à organização do trabalho pedagógico, que inclui o trabalho do professor na dinâmica interna da sala de aula.

No que diz respeito às parcerias com outras instituições para o desenvolvimento de pesquisas e projetos, percebemos que a escola já foi procurada por outras instituições, a exemplo da Universidade de Brasília, da Universidade Estadual de Santa Cruz e da Universidade Federal do Sul da Bahia. No entanto, pelo que foi descrito, os projetos estão paralisados por conta da Pandemia e foi apontado como entrave ao desenvolvimento dos projetos a burocracia e a falta de financiamento para execução dos mesmos.

Buscamos questionar ainda, conforme apresentado no terceiro indicador, sobre as instâncias colegiadas e a atuação do Conselho escolar, das lideranças comunitárias na resolução de demandas. O conselho Escolar é formado por representantes dos docentes, do Cacique e representantes dos pais dos alunos e da comunidade.

Inclusive, percebeu-se uma diferença das escolas não indígenas, que é a presença marcante do Cacique nas decisões da escola. Cabe aqui trazer um fato interessante sobre a escola, que é o Cacique residir ao lado da escola e a sua residência acabar servindo de apoio a escola, professores e alunos, sendo um local bastante receptivo e vivenciado por todos, com as portas sempre abertas. Vale mencionar ainda que o cacique também é docente da escola e preside o Conselho Escolar, possuindo bastante gerência sobre a instituição, sendo sempre consultado sobre as decisões, assim como toda a comunidade.

Importante destacar, a participação das lideranças indígenas na participação de resolução de conflitos e composição das lutas por interesses das comunidades por todo território brasileiro nas últimas décadas, e como ficou demonstrado no caso do CEITAB, o Cacique também desempenha papel com bastante notoriedade e possui grande poder de gerência sobre as mais diversas demandas da comunidade e da escola e também desenvolve um papel importante na luta pelos direitos e interesses dos seus "parentes".

Por fim, no quarto indicador dessa primeira dimensão, foram realizadas perguntas sobre a suficiência de recursos humanos e financeiros para a escola. Restando demonstrado, conforme se vê abaixo que os recursos são insuficientes por tratar-se de uma escola de pequeno porte e que ainda detém dois núcleos com os quais tem que dividir os valores recebidos como verba de manutenção.

No que se refere à quantidade de professores à disposição, grande parte dos entrevistados consideram a quantidade suficiente, mas, percebe-se a dificuldade de professores para lecionarem na área de exatas. A dificuldade maior no que se refere ao grupo de apoio pedagógico é o fato das escolas indígenas não terem o cargo de Coordenador Pedagógico, o que foi citado pela maioria dos entrevistados como algo negativo e que faz extrema falta dentro da instituição escolar. A solução encontrada foi que alguns professores com mais experiências e de áreas diversas se voluntariassem para ajudar os demais. 
Além da ausência do cargo de coordenador escolar, a função de diretor/gestor no momento da pesquisa também estava sendo ocupada por professional não indígena, o que foi pauta de objeção de alguns entrevistados. Bem como, a maior parte dos professores são contratados por Regime Especial de Direito Administrativo (REDA), que é uma contratação que deveria ser excepcional, mas tem se tornado regra dentro da escola indígena, assim, a ocupação dos cargos escolares costuma causar algumas tensões dentro do movimento.

Desta forma, ressalte-se que o primeiro concurso para professores indígenas da Bahia, foi uma grande conquista para o Movimento Indígena do Estado, no entanto ele ainda não foi suficiente para a demanda das escolas. Bem como, há necessidade de novos requisitos ao Edital que se adeque a realidade dos docentes.

$\mathrm{Na}$ dimensão do currículo, através do primeiro indicador que trata sobre a Organização Curricular, buscamos saber se a EA faz parte do PPP, dos planejamentos pedagógicos, bem como sobre as ações educacionais sobre o meio ambiente e se a EA é realizada de forma isolada, inter ou multidisciplinar.

Percebemos assim que a Educação escolar já iniciou os passos para trabalhar questões ambientais de forma interdisciplinar, inclusive isso parece bastante claro aos docentes. No entanto, os entrevistados demonstraram ter dificuldade de entender que a EA deve ser além de interdisciplinar, um processo permanente. Assim, alguns discursos demonstraram que a interdisciplinaridade é trabalhada em alguns eventos e atividades de forma esporádica, mas ainda não alcança a todos e não é contínua e permanente. Ademais, ainda aparece como um dos planos da gestão escolar implementar uma disciplina de Educação Ambiental de maneira isolada, em substituição a disciplina de Educação Digital, o que vai contra a ideia de transversalidade da $E A$, que não deve se destinar como uma nova disciplina do currículo escolar, mas precisa ser uma aliada do currículo, na busca de um conhecimento integrado que supere a fragmentação tendo em vista o conhecimento. Sendo preciso assim repensar o papel da EA, conforme explicita (Lopes, 2021):

(Re)pensar a Educação Ambiental na formação docente exige ainda o reconhecimento do espaço curricular e das práticas pedagógicas desenvolvidas nessa formação. Enquanto área de atuação política não neutra, o currículo pode servir de conservação das ideologias dominantes e de reprodução de uma sociedade dividida em classes, que dominam a natureza e Educação Ambiental a si próprias, assim como pode ser um campo de utopias necessárias à transformação da realidade. 
de forma a aprimorar-se e incorporar novos significados. Até mesmo em razão do dinamismo da sociedade.

A determinação para que a Educação Ambiental seja integrada, contínua e permanente implica o início do seu desenvolvimento na educação infantil sem futura interrupção. Inclusive 0 artigo $2^{\circ}$ da Política Estadual de Educação Ambiental da Bahia, entende por Educação Ambiental o conjunto de processos permanentes e continuados de formação individual e coletiva para a sensibilização, reflexão e construção de valores, saberes, conhecimentos, atitudes e hábitos, visando uma relação sustentável da sociedade humana com o ambiente que integra.

Já Lei 9.795/99 estabelece que a Educação Ambiental deve estar presente, de forma articulada, em todos os níveis e modalidades do processo educativo, respeitando em suas diretrizes nacionais. O princípio citado no artigo 4ํㅜㄴ, inciso VII da Lei 9.795/99, valoriza a abordagem articulada das questões ambientais locais, regionais e nacionais, e o artigo $8^{\circ}$, incisos IV e V incentivam a busca de alternativas curriculares e metodológicas na capacitação da área ambiental e as iniciativas e experiências locais e regionais, incluindo a produção de material educativo (BRASIL, 1999).

A transversalidade, por sua vez, promove uma compreensão abrangente dos diferentes objetos de conhecimento, bem como a percepção da implicação do sujeito de conhecimento na sua produção, superando a dicotomia entre ambos. Por essa mesma via, a transversalidade abre espaços para a inclusão de saberes extraescolares, possibilitando a referência a sistemas de significados construídos na realidade dos alunos (MEC, 1997).

Campiani (2001) afirma que ainda é pouco clara a definição do conceito de transversalidade, suas implantações nas práticas pedagógicas precisam ser esclarecidas. Ainda de acordo com 0 autor, para a capacitação dos professores, devem ser incorporados novos conceitos e metodologias que venham ao encontro da realidade, para que eles sejam atuantes e críticos diante das situações socioambientais e possam atuar e influenciar nas mudanças de atitudes. O engajamento do poder público, da capacitação formal dos professores e do cidadão por meio do exercício da cidadania, deve ser constante.

Porém, para que a transversalidade seja alcançada de forma prática é necessário que sejam eliminadas as barreiras entre as disciplinas e as barreiras entre os profissionais da educação. O que ainda é algo distante da realidade da CEITAB, que apesar de ter um índice satisfatório na Matriz aplicada, ainda necessita de apoio e mudanças para aplicação das práticas de EA. No entanto, esse fator ainda é desafiador para a maioria das escolas do Brasil.

No segundo indicador da dimensão do currículo, perguntamos acerca das atividades e práticas pedagógicas, questionando sobre a prática de atividades inclusivas, a realização de eventos, os recursos utilizados e a realização de 
aulas de campo. Também perguntamos acerca do desenvolvimento de programas e projetos de EA e seu envolvimento com a comunidade.

$\mathrm{Na}$ última dimensão, que trata do espaço físico, perguntamos sobre três indicadores, quais sejam: Território da escola e entorno; Infraestrutura e ambiente Educativo; Ecoeficiência. Assim, no primeiro indicador, perguntamos acerca da utilização dos espaços físicos como ambientes de ensino, aprendizagem e recreação, bem como o uso dos rios locais para trabalhar práticas educativas. De acordo com os entrevistados os espaços físicos são bastante utilizados para recreação e para a aprendizagem.

Segundo Leff (2002 apud BERNARDES; PRIETO, 2010, p. 179) a Educação Ambiental necessita de uma integração de conhecimentos teóricos e práticos para sua compreensão e resolução dos problemas. Assim, revela-se a necessidade de atividades práticas e ligadas ao cotidiano dos estudantes e da comunidade em geral.

No penúltimo indicador foram levantados questionamentos acerca da Infraestrutura e ambiente educativo, no que se refere à acessibilidade, à mobilidade sustentável e à disponibilização de biblioteca.

No indicador acima citado, temos o menor percentual de todos os indicadores e gestão, fato totalmente entendível ao observarmos a infraestrutura do prédio escolar, que conta com três salas de alvenaria e uma sala de taipa e barro, mas que não estão em bom estado de conservação, conta também com dois banheiros que precisam de reforma e adaptação, sobretudo para a volta às aulas após pandemia.

As políticas de acessibilidade vêm ganhando destaque na sociedade, pois facilitam 0 acesso de pessoas deficientes e são garantidas por nossa legislação, a exemplo da a Lei 13.146/2015, que no seu art. 3oㅡㄴ inciso I, determina que entende-se por acessibilidade a possibilidade e condição de alcance para utilização, com segurança e autonomia, de espaços, mobiliários, equipamentos urbanos, edificações, transportes, informação e comunicação, 3 inclusive seus sistemas e tecnologias, bem como de outros serviços e instalações abertos ao público, de uso público ou privados de uso coletivo, tanto na zona urbana como na rural, por pessoa com deficiência ou com mobilidade reduzida (BRASIL, 2015).

No entanto, tal realidade ainda não é presente na escola, que não possui nenhum instrumento de acessibilidade, que atualmente, "é vista como um meio de possibilitar a participação das pessoas nas atividades cotidianas que ocorrem no espaço construído, com segurança, autonomia e conforto" (MORAES, 2007). Assim, a escola estudada fica impedida de vir a receber aluno, professor ou visitante que necessite de acessibilidade. Destaque-se que a ausência de acessibilidade não é um caso isolado a essa escola, mas um problema geral da educação pública. Sobretudo, porque conforme já demonstrado a escola é fruto de um esforço da comunidade, que apesar de buscar melhores condições a escola, ainda não conseguiu sozinha melhoras as condições físicas do prédio escolar.

Revbea, São Paulo, V. 16, № 6: 511-530, 2021. 
Destaque-se que até o momento das entrevistas, após mais de seis meses do início da quarentena por conta do Covid-19, a única alteração realizada para preparar o retorno às aulas foi a instalação de duas pias simples no pátio da escola. Apesar de tratar do anexo, vale ressaltar que um deles ainda não possui sequer um banheiro para uso de alunos e professores.

Um fato positivo e bastante relevante é o fato da escola ter adquirido por meio de doação de uma escola estadual que encerrou suas atividades, livros e estantes para a sua biblioteca literária, no entanto não há na escola espaço físico disponível, pelo que todo material está numa casa emprestada até que se construa um local que possua a infraestrutura necessária.

Segundo SobraL (1982), a pedagogia define biblioteca escolar como força propulsora do processo educacional, instrumento que colabora com as metas educativas e força responsável pelas diversas atividades empregadas no desenvolvimento do currículo. Assim, a escola tem a ganhar com a instalação de uma biblioteca disponível a todos.

Diante da grandeza da rede escolar brasileira, Antunes (1993) afirma que $99 \%$ das escolas brasileiras teriam que fechar as suas portas, se a existência de bibliotecas fosse condição sine qua non para seu funcionamento. Desta forma, apesar da biblioteca ainda não estar fisicamente instalada no prédio escolar da CEITAB, o fato de ao menos já se ter o acervo é algo positivo e uma conquista para todos, vez que possivelmente irá agregar conhecimento aos alunos, professores e todos ao redor.

Por fim, o último indicador trata do uso eficiente dos recursos. Foi perguntado sobre separação e encaminhamento adequado de seus resíduos sólidos, adotadas práticas de economia de energia elétrica, de água e de de material de expediente, bem como a utilização de alimentos orgânicos na preparação da merenda escolar.

Diante de todo o exposto, apesar do percentual da escola em relação aos índices serem satisfatórios, ao analisarmos os discursos dos entrevistados, percebemos que a escola ainda necessita de mudanças que vão desde falta de verbas e financiamentos, até a mudança da matriz curricular e adaptações na estrutura física.

No entanto o Colégio Estadual Indígena Tupinambá do Acuípe de Baixo caracteriza-se de forma positiva como uma instituição que promove espaços de produção e fortalecimento de identidade étnica e cultural do seu povo, das suas tradições e permite o diálogo para a resolução dos problemas que envolvem o seu entorno. Além de que. como já exposto acima, apesar das dificuldades estruturais e administrativas, a escola vem desenvolvendo suas atividades de forma satisfatória, inclusive no que se trata das questões socioambientais.

Saliente-se que por vezes, trabalhar a EA no contexto escolar tem sido um desafio para instituições de todo o país, no entanto, o CEITAB demonstra afinidade com o tema, até em razão da sua integração física e cosmológica com o meio ambiente, pelo que suas atividades se encontram à frente de 
escolas não indígenas, no que se refere a estar em consonância com as políticas públicas da área.

O presente trabalho nos permite inferir que a Educação Ambiental na escola pesquisada possui uma realidade que não é da maioria das escolas, inclusive em razão da sua escola, localização e da cultura na qual está inserida. Apesar da maioria das atividades desenvolvidas na instituição se caracterizarem como EA crítica e estarem em consonância com as Políticas da área de forma satisfatória, ela ainda tem muitos desafios a serem enfrentados.

De forma sugestiva, entendemos que seria relevante a disponibilização de cursos de capacitação e a promoção de atividades contínuas em Educação Ambiental para o corpo docente e discente da escola. Bem como um maior investimento e incentivo a promoção das atividades culturais, inclusive com 0 desenvolvimento de novos levantamentos da EA na Bahia.

Por isso, como perspectivas para continuidade da pesquisa, sugerimos que a mesma ocorra por meio de aplicação desses métodos descritos em diferentes escolas indígenas do Estado da Bahia, de preferência em regiões diversificadas. Vale ressaltar que a Bahia possui cerca de 16 grupos étnicos diferentes, quais sejam: Atikum, Kaimbé, Kantaruré, Kariri-Xocó, Kiriri, Payayá, Pankararé, Pankarú, Pataxó Hãhãhãe, Pataxó, Truká, Tumbalalá, Tupinambá, Tuxá, Xacriabá e Xukuru-Kariri.

Assim, será possível se obter um retrato macro da situação da Educação Ambiental nas escolas indígenas do Estado, que possibilita a fundamentação de uma política pública específica para essas comunidades. Além de que será possível perceber o que de positivo essas escolas indígenas já vêm fazendo e de que forma essas práticas podem ser adotadas por escolas não indígenas.

Frise-se neste momento que os indígenas já possuem em sua cultura originária um comportamento ecologista, conforme podemos perceber na sua própria integração com a natureza, inclusive cosmológica. Razão pela qual em sua maioria já possuem formas de manejo dos seus recursos adequados à conservação da sociobiodiversidade. Daí a importância de se documentar essas práticas para que possam ser levadas para a comunidade em geral, inclusive para a iniciativa privada.

Ademais, os dados obtidos poderão subsidiar a busca por mecanismos que potencializem a sustentabilidade nas suas mais variadas dimensões e 0 domínio de seus territórios, como a construção de projetos locais e até mesmo planos de gestão dos seus recursos, que pode vir a garantir a sustentabilidade social e ambiental das populações que vivem em diversas terras indígenas, levando em consideração a realidade de cada aldeia.

Por fim, interessante trazer que a Educação Ambiental não possui uma fórmula, mas se dá a partir dos seus princípios, e por isso, se mostra necessário a investigação de como são realizadas as práticas pedagógicas de EA nas escolas, para que quando identificadas atividades alinhadas com as 
Políticas Públicas da área, como acontece no CEITAB, elas possam ser replicadas em outras instituições, de acordo com cada contexto escolar.

Assim, será possível também criar espaços de reafirmação e autovalorização daquilo que já é realizado pelas escolas, inclusive, vale frisar que a Escola pesquisada está a frente de outras escolas não indígenas, no que tange ao ensino da Educação Ambiental, o que pode sugerir a necessidade de contato das escolas não indígenas com as escolas indígenas, sendo que o modelo a ser seguido é o da escola indígena, o que poderá inclusive iniciar uma transição paradigmática, já que o padrão de análise de práticas pedagógicas em sua maioria se dão de forma contrária, que utiliza-se as categorias cosmológicas externas para analisar e entender as cosmologias indígenas. superando paradigmas impostos pela visão mecanicista da pedagogia tradicional.

Agradecimentos: À Fundação de Amparo à Pesquisa do Estado da Bahia, pelo financiamento; à Universidade Federal do Sul da Bahia, por tornar possível o estudo do autor.

\section{Referências}

ANTUNES, W. A. Bibliotecas escolares: curso de Capacitação do professor regente de biblioteca. Brasília: CORBI, 1993.

BAHIA, Política Estadual de Educação Ambiental - Lei 12.056/11. Salvador: Secretaria do Meio Ambiente/Diretoria de Educação Ambiental para a Sustentabilidade. Disponível em: <https://governoba.jusbrasil.com.br/legislacao/1026482/lei-12056-11>. Acesso em 13/05/2020.

BAHIA, Órgão Gestor da Política Nacional de Educação Ambiental. Programa Nacional de Formação de Educadoras(es) Ambientais: por um Brasil educado e educando ambientalmente para a sustentabilidade, ProFEA. Brasília: Série Documentos Técnicos, n. 8, 2006.

BAHIA, Política Nacional de Educação Ambiental - Lei 9.795/99. Presidência da República, Brasília, 1999. Disponível em: $<$ http://www.planalto.gov.br/ccivil 03/leis/19795.htm>. Acesso em: 05/06/19.

BAHIA, Constituição (1988). Constituição da República Federativa do Brasil: promulgada em 5 de outubro de 1988.

CAMPIANI, M.C. Os temas transversais na educação. S.Paulo: Códex, 2001.

CARVALHO, I. C. M. Educação Ambiental Crítica: nomes e endereçamentos da educação. In.: Identidades da Educação Ambiental Brasileira. Brasília: Ministério da Educação, 2004. Disponível em: <http://www.mma.gov.br/ estruturas/educamb/- arquivos/livro ieab.pdf $>$. Acesso em: 15/11/2018 
COSTA-PINTO, A. Potência de agir e Educação Ambiental: aproximações a partir de uma análise da experiência do Coletivo Educador Ambiental de Campinas (Coeduca). 2002. Tese (Doutorado) - USP, São Paulo, 2002.

ESTEBAN, M. P. S. Pesquisa qualitativa em educação: fundamentos e tradições. Porto Alegre: AMGH, 2010.

ADOTTI, M. O projeto político-pedagógico na escola: na perspectiva de uma educação para a cidadania. Brasília: Cortez, 1994.

LEFF, Enrique. Epistemologia ambiental. São Paulo: Cortez, 2006.

LOPES, T.S.; ABILIO, F.J.P. Educação Ambiental Crítica: (re)pensar a formação inicial de professores/as. Revista Brasileira de Educação Ambiental, v. 16, p. 38-58, 2021.

MINAYO, M. C. S.; SANCHES, O. Quantitativo-qualitativo: oposição ou Complementaridade? Cad. Saúde Pública, São Paulo, v. 9, n. 3, p. 239-262, 1993.

MORAES, M. C. Acessibilidade no Brasil: Análise da NBR 9050. $175 f$. Dissertação (Mestrado em Arquitetura e Urbanismo) - Centro Tecnológico, Universidade Federal de Santa Catarina - UFSC. Florianópolis, 2007.

PEDRINI, A. G. O estudo de caso como unidade metodológica na Educação Ambiental. In: PEDRINI, A. G. (Org). Metodologias em Educação Ambiental. Petrópolis: Vozes, 2007. p. 74-91.

ROSENAU, C.R. Ação do gestor escolar: estudo de caso com o desenvolvimento de proposta pedagógica. Florianópolis: UFSC, 2002. $99 f$. Dissertação (mestrado em Engenharia de Produção). Universidade Federal de Santa Catarina.

SOBRAL, E.B. Recursos humanos para a biblioteca escolar. Anais do Seminário Nacional Sobre Bibliotecas Escolares, 1982, Brasília. Brasília: INL/UNB, 1982. p. 88-108.

STAKE, R. The art of case study research. Thousand Oaks, Sage Publications, p. 175, 1995.

TASSINARI, A.M.I.; COHN, C. Escolarização indígena entre os Karipuna e Mebengokré-Xikrin: uma abertura para o outro. In: TASSINARI, A.M.I; GRANDO, B.S.; ALBUQUERQUE, M.A.S. (Orgs.) Educação indígena: reflexões sobre noções nativas de infância, aprendizagem e escolarização. Florianópolis: UFSC, 2012.

VEIGA, I.P.A. Projeto político-pedagógico da escola: uma construção possível. Campinas: Papirus, 2009.

VIEIRA, S.R.; CAMPOS, M.A.T.; MORAIS, J. L.; Proposta de matriz de indicadores de Educação Ambiental para avaliação da sustentabilidade socioambiental na escola. Rev. Eletrônica Mestr. Educ. Ambient. E-ISSN 1517-1256, v. 33, n.2, p. 106-123, maio/ago., 2016. 